\title{
EFEITO DE DIFERENTES CONCENTRAÇÕES DE CLORETO DE CÁLCIO NA QUALIDADE DO ABACAXI "PÉROLA" MINIMAMENTE PROCESSADO"
}

\author{
GLEUCIA CARVALHO SILVA², GERALDO ARRAES MAIA³, MEN DE SÁ MOREIRA DE SOUZA FILHO ${ }^{4}$, RAIMUNDO \\ WILANE DE FIGUEIREDO ${ }^{3}$, HELOISA ALMEIDA CUNHA FILGUEIRAS ${ }^{4}$, ARTHUR CLAUDIO RODRIGUES DE SOUZA ${ }^{4}$
}

\begin{abstract}
RESUMO - O objetivo deste trabalho foi avaliar o efeito do cloreto de cálcio $\left(\mathrm{CaCl}_{2}\right)$ na qualidade do abacaxi "Pérola" minimamente processado e refrigerado. Os frutos foram lavados e sanifizados, sendo em seguida cortados na forma de trapézio e fatia, imersos em solução de $\mathrm{CaCl}_{2}$, embalados em polipropileno rígido e armazenado a $4^{\circ} \mathrm{C}$ por 16 dias. As variáveis SST, perda de massa fresca, textura e $\mathrm{pH}$ foram influenciadas pelas concentrações de $\mathrm{CaCl}_{2}$. O tempo de armazenamento afetou a ATT (Acidez total titulável), SST (Sólidos solúveis totais), ART (Açúcares redutores totais), perda de massa fresca, textura, $\mathrm{pH}$. Os resultados revelaram que, independente do tipo de corte, não houve diferença significativa entre os tratamentos com $1 \%$ e 2,5\% , tendo ambos preservado as características de qualidade.

Termos de indexação: Ananas comosus, processamento mínimo, armazenamento.

\section{EVALUATION OF THE EFFECT OF DIFFERENT CONCETRATIONS OF CALCIUM CHLORIDE IN THE QUALITY OF PINEAPPLE "PÉROLA" MINIMALLY PROCESSED AND REFRIGERATED}

ABSTRACT - The purpose of this work was to evaluate the effect of calcium chloride $\left(\mathrm{CaCl}_{2}\right)$ in the quality of pineapple "pérola" minimally processed and refrigerated. The fruits were washed, sanitized, cutted and imbebed in a calcium chloride solution and packed in rigid polypropylene and stored at $4^{\circ} \mathrm{C}$ for 16 days. The variables SS, loss of weight, texture and $\mathrm{pH}$ were influenced by the concentration of $\mathrm{CaCl}_{2}$ The storage time affected TTA(Total titrable acidity), SS (Soluble solids), TRS (Total reducing sugars), loss of weight, texture and $\mathrm{pH}$. The results showed that independent of the type of cut there was not a significant difference between the treatments with $1 \%$ and $2.5 \%$ having both preserved the quality characteristics.

Index terms: Ananas comosus, minimally processed, storage.

\section{INTRODUÇÃO}

Os produtos minimamente processados são também conhecidos como fresh-cut com utilização recente no Brasil, sendo sua produção iniciada na década de 90 por algumas empresas atraídas pelas novas tendências do mercado. O valor agregado pelo processamento mínimo aumenta a competitividade do setor produtivo e propicia meios alternativos para a comercialização de frutos (Chitarra, 1999).

Apesar dos frutos e hortaliças minimamente processados apresentarem-se convenientemente com características similares à matériaprima, os tecidos vegetais in natura, bem como seus produtos minimamente processados respiram após o processamento. Estes produtos deterioram-se rapidamente, perdendo qualidade, especialmente cor e textura, como resultado da liberação de enzimas endógenas, aumento da taxa de respiração e crescimento microbiano, levando também a uma redução da vida útil do mesmo (Wiley, 1997). Estas alterações indesejáveis na qualidade são aceleradas por danos mecânicos às células, causados pelas operações de descasque e corte, o que permite o contato das enzimas com o substrato (King \& Bolin, 1989).

O cálcio é um elemento muito importante para a estrutura e funcionamento da parede celular e membranas, sendo o responsável por uma série de alterações como a deterioração acentuada das membranas causada por uma deficiência de cálcio e mudanças na permeabilidade à passagem de água causada por modificações na estrutura das membranas (Chitarra \& Chitarra, 1990).

Segundo Rolle \& Chism (1987), a presença de sais de cálcio no fruto implica em grandes vantagens como um retardamento da respiração celular e um aumento na firmeza.

O objetivo deste trabalho foi avaliar os efeitos produzidos pela adição de cloreto de cálcio nas características físicas e físico-químicas do abacaxi "Pérola" minimamente processado nas formas de trapézio e fatia, armazenado $4^{\circ} \mathrm{C}$.

\section{MATERIALEMÉTODOS}

Os frutos de abacaxi "Pérola" foram colhidos com qualidade e ponto de maturação "pintado", e em seguida, recepcionados e lavados inicialmente com água potável para retirada de areia, material aderido à casca e em seguida imediatamente imersos em tanques contendo água clorada com 200 ppm de cloro ativo por 2 minutos para desinfecção da casca. Os frutos foram armazenados a $12^{\circ} \mathrm{C}$ por aproximadamente 15 horas, objetivando a estabilização interna do mesmo para posterior processamento.

A uma temperatura ambiente de $12^{\circ} \mathrm{C}$, os frutos foram descascados e cortados mecanicamente, em máquinas descascadora e fatiadora nas formas de trapézio e fatia, com espessura de $1 \mathrm{~cm}$, sendo retirado manualmente o cilindro central. O corte tipo trapézio foi realizado com o auxílio de facas em aço inox. Após estas operações, os cortes foram submetidos aos experimentos I e II, efeito do cálcio - imersão dos cortes tipo trapézio (exp. I) e fatia (exp.II) em soluções contendo 20 ppm de hipoclorito de sódio e cloreto de cálcio $\left(\mathrm{CaCl}_{2}\right)$ em diferentes concentrações $(0 \%, 1 \%$ e 2,5\%) por 15 segundos. Os produtos obtidos foram embalados em recipientes retangulares de polietileno tereftalatado (PET) transparentes, com tampa (NEOFORM@ N-94) e capacidade para $200 \mathrm{~g}$ do produto.

As amostras foram submetidas às seguintes determinações: $\mathrm{pH}$, medidor de pH HANNA INSTRUMENTS, modelo HI 9321, (AOAC,1992); acidez total titulável (ATT), (IAL, 1985); sólidos solúveis totais (SST), através de leitura em refratômetro digital ATAGO, modelo PR-101, com escala de 0 a $45^{\circ}$ Brix; açúcares redutores totais (ART), (Miller, 1959); textura, medido diretamente em texturômetro STABLE MICRO SYSTEM, modelo TA-SXT2; perda de massa fresca determinada em percentagem, considerando-se a diferença entre o peso da embalagem contendo as amostras do tempo 0 e aquele obtido em cada intervalo de tempo. Usou-se balança semi-analítica com precisão de $0,5 \mathrm{~g}$; atividade de água, através do medidor de Aw AQUALAB, modelo CX-2 e umidade, AOAC (1992).

Os experimentos foram realizados em delineamento inteiramente casualizado (DIC), obedecendo o esquema fatorial 3 x 5 , tendo como fatores a concentração de $\mathrm{CaCl}_{2}$ e tempo de armazenamento.

Foram realizadas 3 repetições, sendo cada uma representada por uma embalagem. Cada embalagem com 20 pedaços para o corte tipo trapézio ou 10 pedaços para o tipo fatia.

A partir dos resultados de análise de variância e verificando-se as interações entre os fatores, o tempo foi desdobrado dentro de cada concentração de $\mathrm{CaCl}_{2}$ e os resultados submetidos a regressão polinomial,

\footnotetext{
${ }^{1}$ (Trabalho 001/2003). Recebido: 05/01/2003. Aceito para publicação: 30/05/2003.

${ }^{2}$ Eng $^{\text {a }}$. de Alimentos. Aluna do Curso de Mestrado em Tecnologia de Alimentos/UFC.

${ }^{3}$ Professores do Departamento de Tecnologia de Alimentos, Universidade Federal do Ceará, C.P. 12138, CEP 60356-000, Fortaleza, CE. E-mail: frutos@ ufc.br.

${ }^{4}$ Pesquisadores da EMBRAPA Agroindústria Tropical - Fortaleza, Ceará. sa@ cnpat.embrapa.br
} 
considerando-se equações de até $3^{\circ}$ grau. $\mathrm{O}$ coeficiente de determinação mínimo para a utilização das curvas foi de 0,70 .

\section{RESULTADOSEDISCUSSÃO}

Para o corte tipo trapézio, observou-se interação significativa apenas para o pH. Verificou-se ainda o efeito do cloreto de cálcio nos sólidos solúveis totais, perda de massa fresca e textura e o tempo de armazenamento na atividade de água, na acidez total titulável, nos sólidos solúveis totais, nos açúcares redutores totais, na perda de massa fresca e na textura.

O corte tipo fatia apresentou interação significativa para as características umidade, acidez total titulável, açúcares redutores totais e textura. O cloreto de cálcio influenciou as características $\mathrm{pH}$, sólidos solúveis totais e perda de massa fresca; e o tempo de armazenamento influenciou a atividade de água, $\mathrm{pH}$, sólidos solúveis e perda de massa fresca.

Na Figura 1 encontram-se os resultados para a atividade de água nos cortes de abacaxis em trapézio e fatia. Observou-se uma redução nos níveis da atividade de água com o tempo de armazenamento para ambos os cortes. O corte tipo trapézio variou de 0,989 a 0,983 e o tipo fatia de 0,990 a 0,986. A redução foi mais elevada nos abacaxis cortado em trapézio que em fatia, fato este em consequiência do corte trapézio possuir uma maior área de exposição, o que induz a um maior dano mecânico.

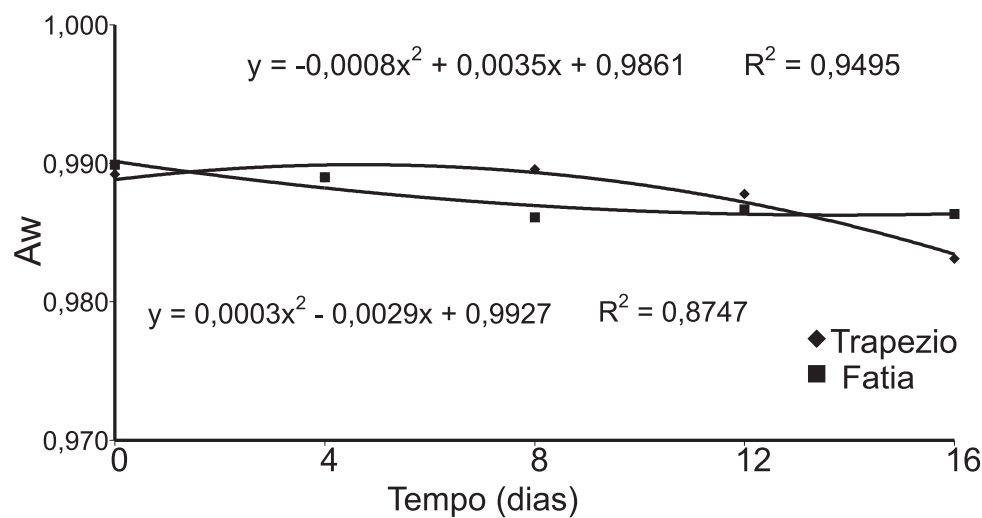

FIGURA 1 -Atividade de água ( $\mathrm{Aw}$ ) para abacaxis minimamente processados na forma de trapézio e fatia tratados com $\mathrm{CaCl}_{2}$ armazenados a $4^{\circ} \mathrm{C} \pm 1^{\circ} \mathrm{Ce} 99 \%$ UR por 16 dias

Observou-se uma interação significativa entre o tempo de armazenamento e as diferentes concentrações de cloreto de cálcio para o corte tipo fatia (Figura 2). A concentração de $1 \% \mathrm{de} \mathrm{CaCl}_{2}$ foi a única que exerceu influência sobre os corte em fatia, apresentando ao final do período de armazenamento uma menor umidade $(83,13 \%)$. As concentrações de $0 \%$ e $2,5 \%$ de $\mathrm{CaCl}_{2}$ não exerceram nenhuma influência.

Na Figura 3 encontram-se os resultados para os cortes tipos trapézio e fatia tratados com $\mathrm{CaCl}_{2}$. Não foi observada diferença significativa entre os tratamentos com 1,0 e 2,5\% de $\mathrm{CaCl}_{2}$ para ambos os tipos de cortes.

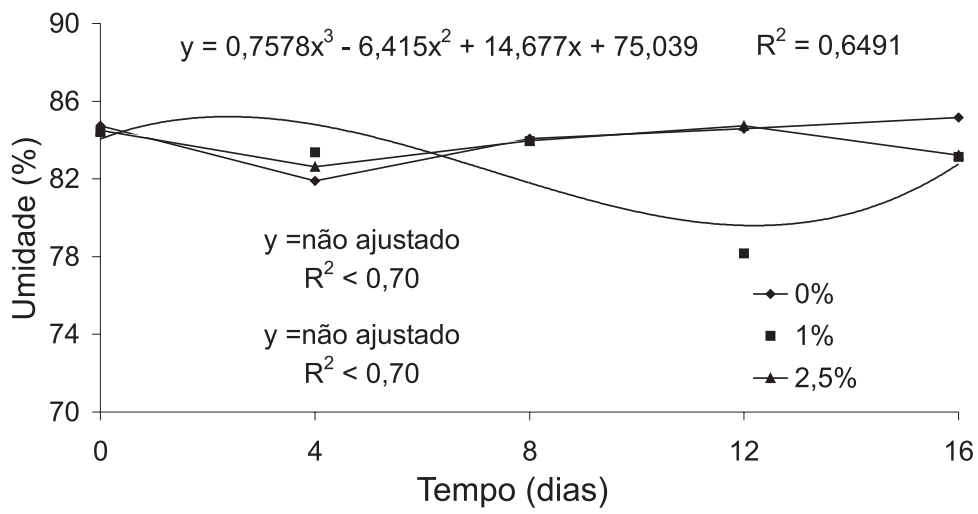

FIGURA 2 -Umidade para abacaxis minimamente processados na forma de fatia tratados com diferentes concentrações de $\mathrm{CaCl}_{2}$ armazenados a $4^{\circ} \mathrm{C} \pm 1^{\circ} \mathrm{Ce} 99 \%$ UR por 16 dias.

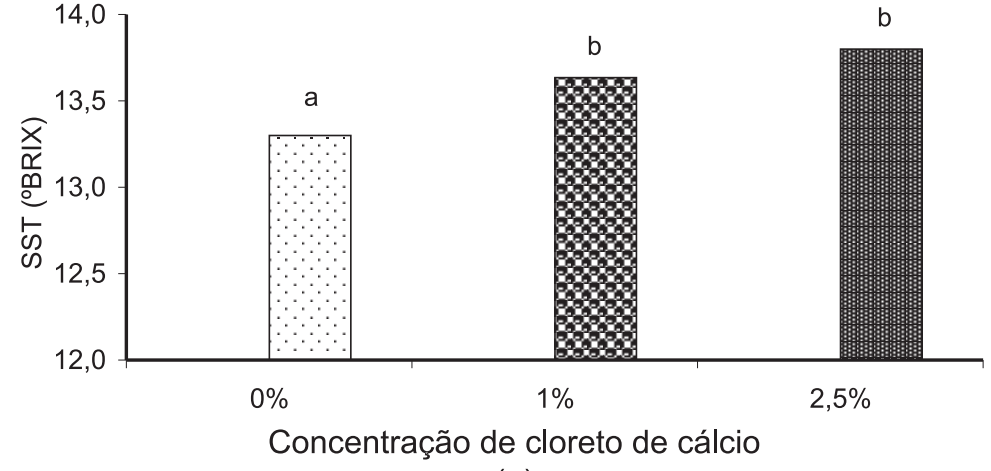

(a)

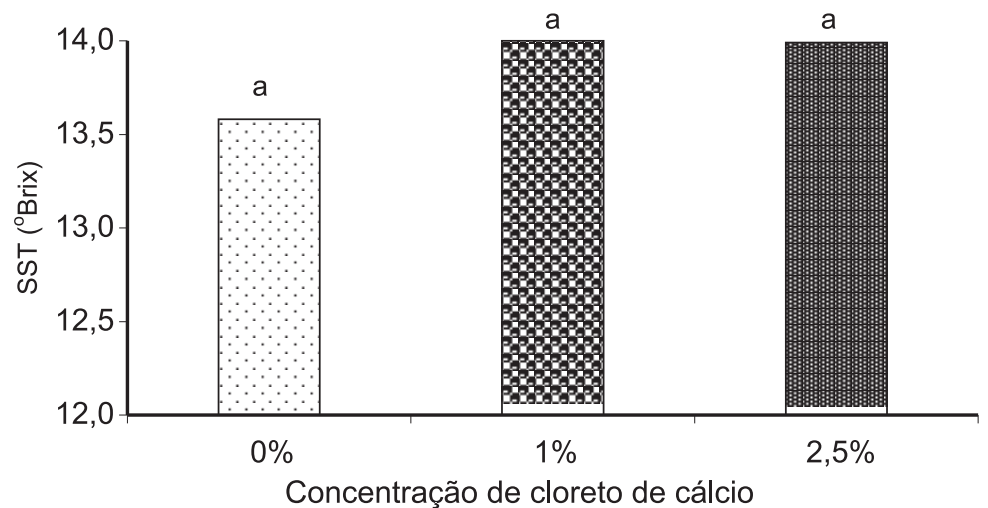

(b)

FIGURA 3-Sólidos solúveis totais para abacaxis minimamente processados na forma de trapézio (a) e fatia (b) tratados com diferentes concentrações de cloreto de cálcio armazenados a $4^{\circ} \mathrm{C} \pm$ $1^{\circ} \mathrm{C} \mathrm{e} 99 \%$ UR por 16 dias.

Carvalho (2000) trabalhando com kiwis minimamente processados tratados com cloreto de cálcio a $1 \%$, cortados em fatias e armazenados a $1^{\circ} \mathrm{C}$ por 10 dias, verificou uma redução nos teores de SST ao longo do tempo de armazenamento.

As concentrações $0 \%$ e $1 \%$ de cloreto de cálcio apresentaram uma oscilação de açúcares redutores totais durante o armazenamento, no entanto, os cortes tratados com 2,5\% obtiveram uma redução de $12,50 \%$ para 11,89\% (Figura 4). Os cortes de abacaxi em trapézio apresentaram uma redução durante o armazenamento de 12,91 para 11,23

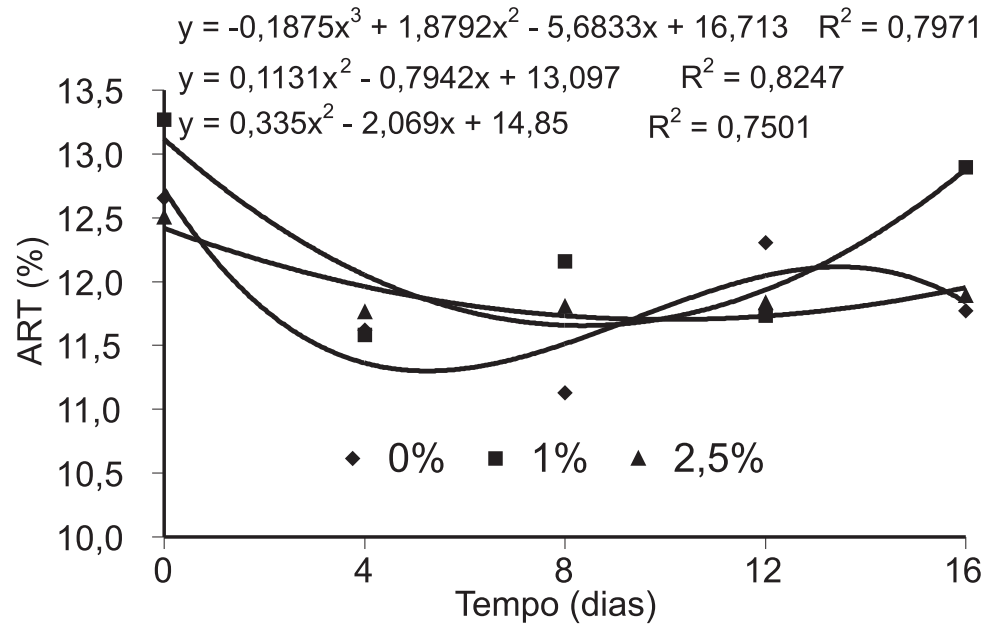

FIGURA 4 - Açúcares redutores totais para abacaxis minimamente processados na forma de trapézio e fatia tratados com cloreto de cálcio armazenados $\mathrm{a} 4^{\circ} \mathrm{C} \pm 1^{\circ} \mathrm{C}$ e $99 \%$ UR por 16 dias.

Segundo Watada et al. (1990), a redução nos teores de açúcar pode ser devido a um aumento da produção de etileno com elevação da taxa respiratória, ocasionada pelas operações de descasque e corte, onde possibilita a redução dos substratos de reserva.

Carvalho (2000) trabalhando com kiwis verificou uma ligeira re- 
dução nos teores de açúcar com o tempo de armazenamento, sendo mais acentuada nos dois primeiros dias de armazenamento as fatias tratadas com $1 \%$ de cloreto de cálcio.

Analisando os resultados referentes ao $\mathrm{pH}$ (Figura 5) verifica-se que a aplicação de cloreto de cálcio refletiu de maneira significativa nos cortes de abacaxi tipo fatia, tendo a concentração de $2,5 \%$ de cloreto de cálcio apresentado um menor valor (3,58). Prado et al (2000 b) avaliando o efeito do cloreto e cálcio $1 \%$ sobre a qualidade do abacaxi c.v. Smooth cayenne verificou que o $\mathrm{pH}$ aparentemente não foi afetado pelo cálcio.

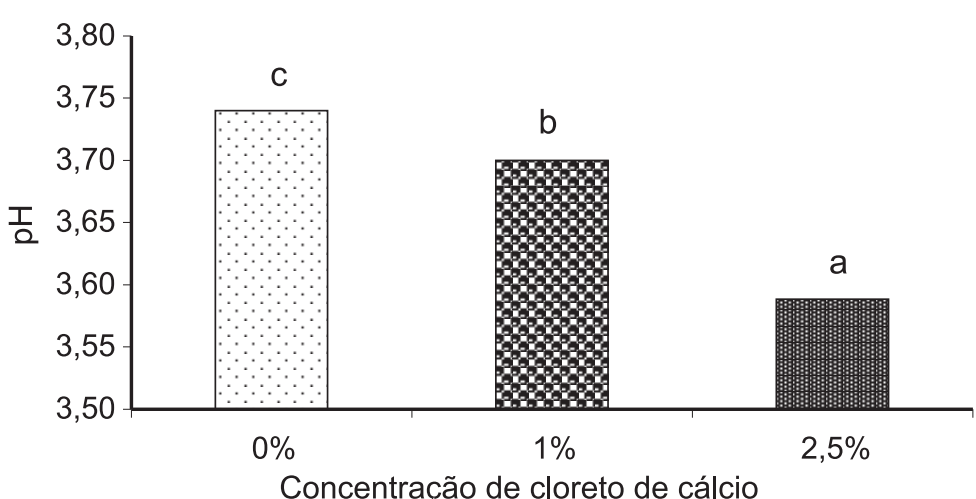

FIGURA 5-pH para abacaxis minimamente processados na forma de fatia tratados com diferentes concentrações de cloreto de cálcio armazenados a $4^{\circ} \mathrm{C} \pm 1^{\circ} \mathrm{C}$ e $99 \%$ UR por 16 dias.

Na Figura 6 verifica-se que todas as concentrações apresentaram reduções no $\mathrm{pH}$, tendo os cortes tratados com $2,5 \%$ de cloreto de cálcio apresentados um menor valor $(3,36)$. Estes resultados encontram-se dentro da variação de 3,0 a 4,0 citada por Chada et al. (1972) para abacaxis.

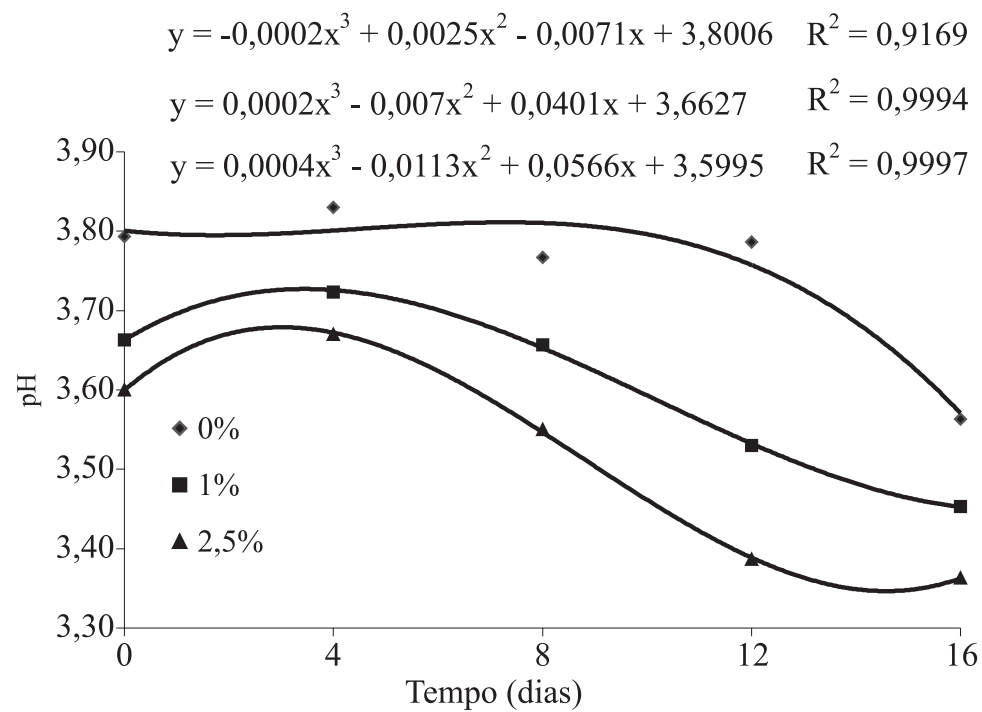

FIGURA 6-pH para abacaxis minimamente processados na forma de trapézio tratados com diferentes concentrações de cloreto de cálcio e armazenados a $4^{\circ} \mathrm{C} \pm 1^{\circ} \mathrm{Ce} 99 \%$ UR por 16 dias.

Na Figura 7 observou-se que a ATT aumentou independente da concentração de cloreto de cálcio. Os cortes tratados com $0 \%$ e $1 \%$ de cloreto de cálcio apresentaram valores para acidez menores e muito próximos, e para a acidez nos pedaços de abacaxis cortados em fatias tratados com $2,5 \%$, um valor mais elevado $(0,65)$. Verifica-se também que a acidez nos pedaços tratados com $1 \%$ apresentou uma grande variação ao final dos 16 dias de armazenamento.

Segundo Botrel (1994), a acidez pode variar no interior do fruto. Durante o amadurecimento aumenta da base para o topo, isto é, a acidez é mais elevada na região próxima à casca do que no cilindro central.

Em trabalhos realizados com kiwis minimamente processados, fatiados e tratados com $1 \%$ de cloreto de cálcio, Carvalho (2000) observou que a ATT mostrou-se afetada significativamente pelo período de armazenamento e concentração de cálcio.
Prado et al. (2000 b) encontrou resultados diferentes trabalhando com abacaxis c.v. Smooth cayenne, onde verificou que os cortes não foram afetados pela concentração de $1 \%$ de cloreto de cálcio.

$\mathrm{Na}$ Figura 8 verificou-se que as fatias de abacaxis tratadas com $1 \%$ de cloreto de cálcio apresentaram uma textura mais elevada ao final do experimento $(0,980 \mathrm{Kg})$, o que representa uma maior firmeza em comparação com os demais tratamentos.

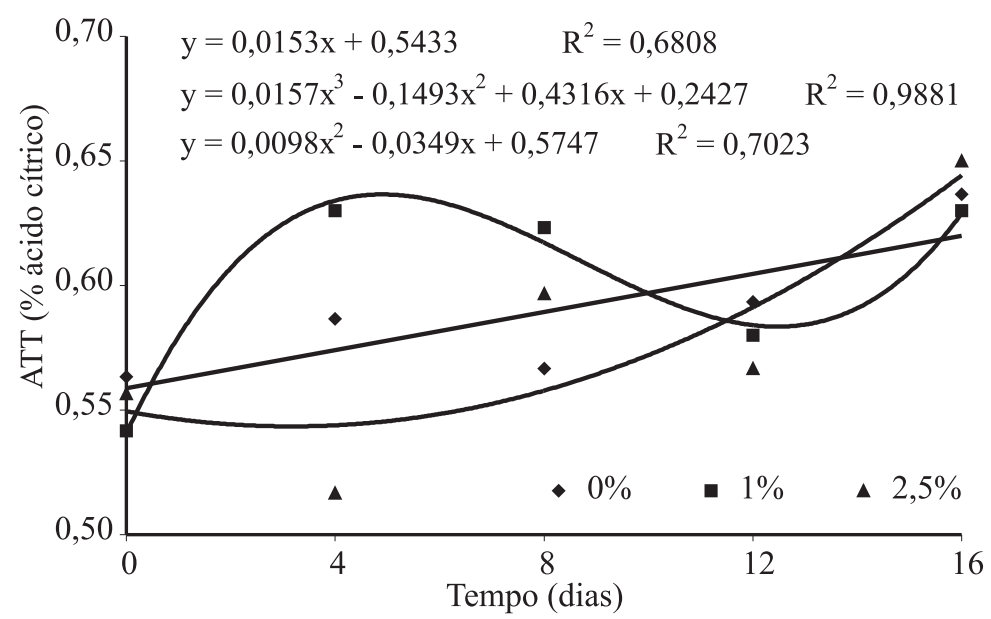

FIGURA 7-Acidez total titulável para abacaxis minimamente processados na forma de fatia e tratados com diferentes concentrações de cloreto de cálcio e armazenados a $4^{\circ} \mathrm{C} \pm 1^{\circ} \mathrm{C}$ e $99 \%$ UR por 16 dias.

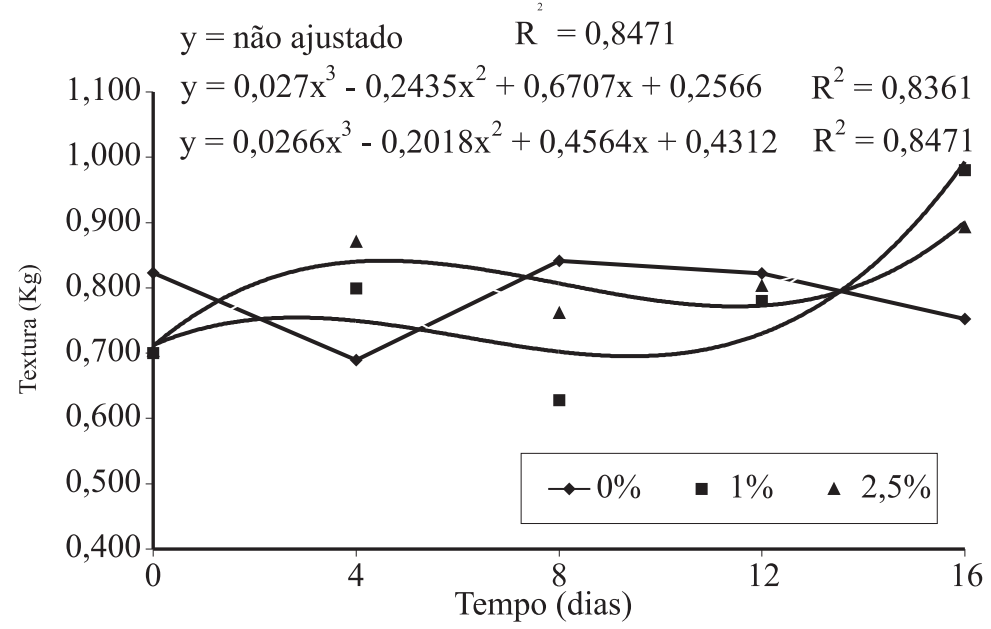

FIGURA 8-Textura para abacaxis minimamente processados na forma de fatia tratados com diferentes concentrações de cloreto de cálcio e armazenados a $4^{\circ} \mathrm{C} \pm 1^{\circ} \mathrm{C}$ e $99 \%$ UR por 16 dias.

Resultado semelhante encontrou PRADO et al. (2000 b) com abacaxis Smooth cayenne minimamente processados, onde a concentração de $1 \%$ de cloreto de cálcio promoveu melhor manutenção da textura.

King \& Bolin (1989) afirmaram que perdas de textura refletem em alterações indesejáveis na qualidade, as quais são aceleradas por danos mecânicos causados às células pelas operações de descasque e corte, possibilitando assim um contato das enzimas com o substrato.

Através da Figura 9 constatou-se que os cortes tratados com $1 \%$ e $2,5 \%$ não apresentaram diferença significativa entre os cortes tratados com cloreto de cálcio.

Miranda et al. (2000) em trabalhos com mamões minimamente processados verificaram que os pedaços de frutos tratados com $2 \%$ de cloreto de cálcio foi suficiente para manutenção das substâncias pécticas e consequentemente melhor textura.

$\mathrm{Na}$ Figura 10 encontram-se os resultados para perda de massa fresca dos cortes de abacaxis tipo trapézio e fatia. Observou-se uma diferença significativa entre os dois cortes e as diferentes concentrações de cloreto de cálcio, tendo os cortes trapézio apresentado uma maior perda de massa fresca que os em fatia. Os pedaços de abacaxis cortados em 
trapézio tratados com $2,5 \%$ de cloreto de cálcio apresentaram uma maior perda de massa fresca $(1,367 \%)$. Nos cortes em fatia, pelo contrário, a perda de massa fresca foi bem menor $(0,196 \%)$. Não se verificou diferença estatística entre os corte em trapézio tratados com $1 \%$ e 2,5\%.

Estes resultados revelaram que por apresentar uma área de exposição bem maior, as perdas de peso dos cortes em trapézio foram maiores que os cortados em fatia. É possível que o tempo de imersão de 15 segundos não tenha sido suficiente para promover melhor penetração do cloreto de cálcio no tecido vegetal.

Carvalho (2000) realizou trabalhos com kiwis minimamente processados e não verificou diferença significativa entre as fatias tratadas com cloreto de cálcio e ácido cítrico. No tratamento com cloreto de cálcio a $1 \%$ verificou-se perda de massa fresca ao longo dos 10 dias de armazenamento.

O tempo de armazenamento também influenciou a perda de massa fresca em ambos os tipos de cortes, sendo que o corte tipo fatia apresentou uma menor perda de massa fresca $(0,467 \%)$ em relação ao tipo trapézio $(1,272 \%)$ (Figura 11).

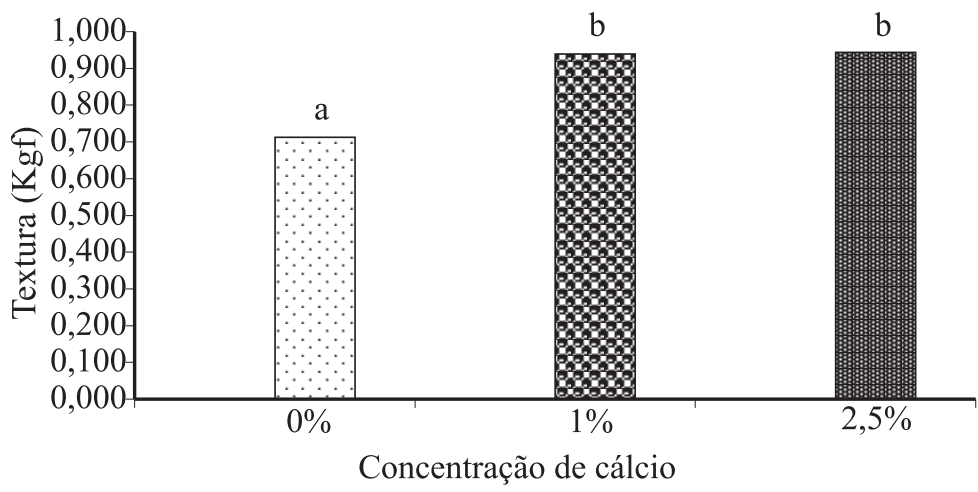

FIGURA 9-Textura para abacaxis minimamente processados na forma de trapézio tratados com diferentes concentrações de cloreto de cálcio e armazenados a $4^{\circ} \mathrm{C} \pm 1^{\circ} \mathrm{C}$ e $99 \%$ UR por 16 dias.

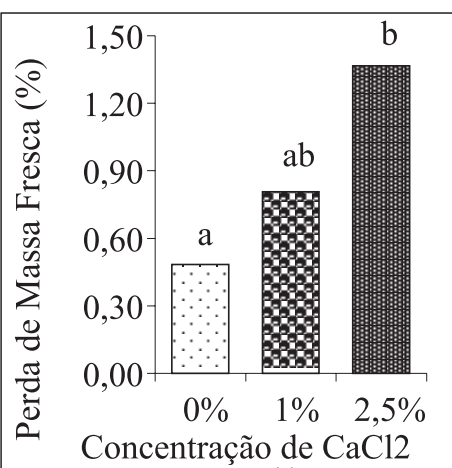

(a)

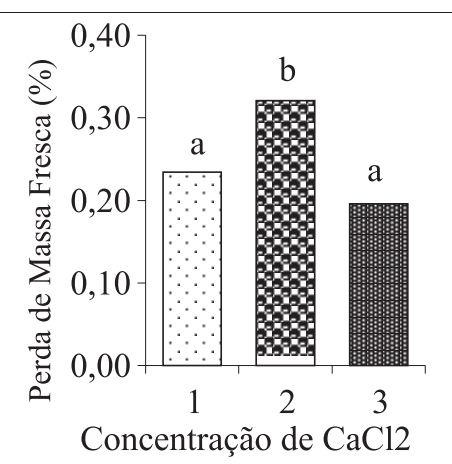

(b)
FIGURA 10-Perda de massa fresca para abacaxis minimamente processados na forma de trapézio (a) e fatia (b) tratados com diferentes concentrações de cloreto de cálcio e armazenados a $4^{\circ} \mathrm{C} \pm 1^{\circ} \mathrm{C}$ e $99 \%$ UR por 16 dias.

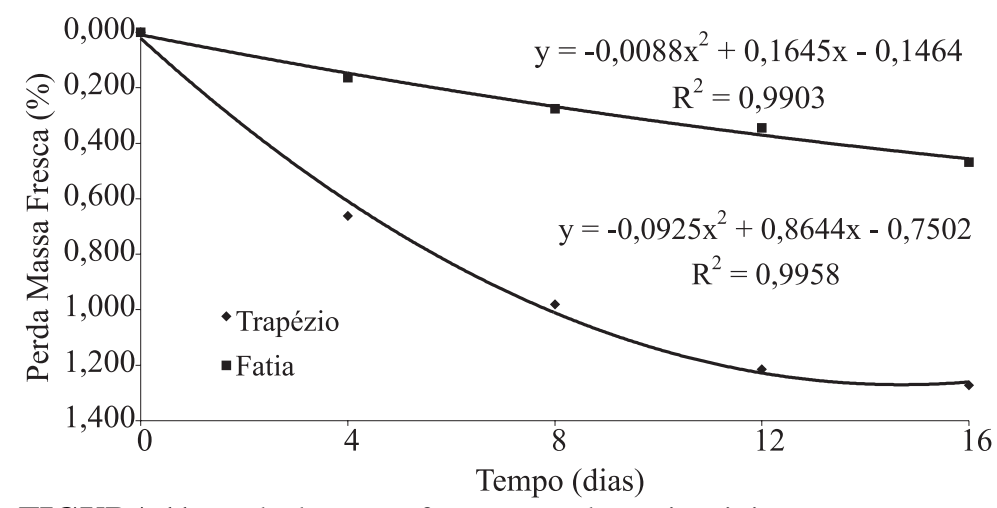

FIGURA 11-Perda de massa fresca para abacaxis minimamente processados na forma de trapézio e fatiados.
A perda de massa fresca pode ser atribuída, principalmente, à perda de umidade e de material de reserva pela transpiração e respiração (Carvalho, 2000).

\section{CONCLUSÕES}

1) De acordo com os resultados obtidos das características avaliadas, observou-se, para os cortes em trapézio, não haver diferença entre os pedaços tratados com $1 \%$ e $2,5 \%$, para as determinações de perda de massa fresca e textura, sendo indicado portanto um tratamento com $1 \%$ de cloreto de cálcio. No corte tipo fatia, para a perda de massa fresca, a concentração de $1 \%$ de cloreto de cálcio apresentou um resultado mais significativo que os demais tratamentos. Portanto, o corte tipo fatia é o mais indicado para o processamento mínimo de abacaxi, visto que este tipo de corte apresentou um melhor comportamento durante o período de armazenamento, sendo apto para o consumo.

\section{REFERÊNCIAS BIBLIOGRÁFICAS}

ASSOCIATION OF OFFICIAL ANALYTICAL CHEMISTRY . Official Methods of Analysis of the Association of Official Analytical Chemistry . 12. ed.. Washington, 1992.

BOTREL, N. ; ABREU, C.M.P. Colheita, cuidados e fisiologia póscolheita do abacaxi. Informe Agropecuário, Belo Horizonte, v.17, n.139, p.33-40, 1994.

CARVALHO, A.V. Avaliação da qualidade de kiwis c.v. Hayward minimamente processados. 2000. 86f. Dissertação (Mestrado em Ciências dos Alimentos) - Universidade Federal de Lavras, Lavras, 2000.

CHADA, K.L. et al.. Biochemical changes with growth and development of pineapple-kew. 1. Changes in physicochemical constituints. The Indian Journal of Horticultural, Benglore, v.29, n.1, p. 54-57, 1972.

CHITARRA, M.I.F.; CHITARRA, A.B. Pós-colheita de frutos e hortaliças: fsiologia e manuseio. Lavras: ESAL/FAEPE, 1990. 320p.

CHITARRA, M.I.F. Processamento mínimo de frutas e hortaliças. Tecnologia e Treinamento Agropecuário, n.10, p.7, 1999.

INSTITUTO ADOLFO LUTZ. Normas analíticas, métodos químicos e físicos para análise de alimentos . 3. ed. São Paulo, 1985. v.1, 533p.

KING, A. D.; BOLIN, H.R.. Physiological and microbiological storage stability of minimally processed fruits and vegetables. Food Technology, Chicago, p.132-135, 1989.

MILLER, G.L. Use of dinitrosalicycle acid reagent for determination of reducing sugars. Analytical Chemistry, Washington, n.31, p.26-428, 1959.

MIRANDA, R.B. et al. Avaliação da qualidade de mamões (Carica papaya $\mathrm{L}$.) de entre-safra minimamente processados. In: ENCONTRO DE PROCESSAMENTO MÍNIMO DE FRUTAS E HORTALIÇAS, 2., 2000, Viçosa. Anais... Viçosa: UFV, 2000. p.18.

PRADO, M.E.T.P. et al. Abacaxi "Smooth cayenne" minimamente processado. In: ENCONTRO DE PROCESSAMENTO MÍNIMO DE FRUTAS E HORTALIÇAS, 2., 2000, Viçosa. Anais... Viçosa: UFV, 2000b. p.6.

ROLLE, R.; CHISM, G.W. Physiological consequences of minimally processed fruits and vegetables. Journal of Food Quality, Oxford, v.10, p.157-177, 1987.

WATADA, A.; ABE, K.; YAMAUCHI, N. Physiological activities of partially processed fruits and vegetables . Food Technology, Chicago, n.20, p.116-122, 1990.

WILEY, R.C. Frutas y hortalizas minimamente procesadas y refrigeradas . Zaragoza: Acribia, 1997.361p. 